\title{
Nasal Polyp with Heterotopic Bone Formation (Osseous Metaplasia): A Case report
}

\author{
Minoo Shafii ${ }^{1}$, Minoo Saatian ${ }^{1}$, Farid Aliehyaii ${ }^{2}$, Ehsan Jangholi ${ }^{3 凶}$, Reza Najibpour ${ }^{4}$, Ali Farshad ${ }^{4}$
}

'Department of Pathology, Islamic Azad University, Medical Tehran Branch, Tehran, Iran

${ }^{2}$ Department of ENT, Islamic Azad University, Medical Tehran Branch, Tehran, Iran

${ }^{3}$ Young Researchers Club, Tehran Medical Branch, Islamic Azad University, Tehran, Iran

${ }^{4}$ Students' Research Committee, Tehran Medical Branch, Islamic Azad University, Tehran, Iran

\begin{abstract}
Osseous metaplasia is defined by the presence of heterotopic normal bone tissue in a soft tissue. Metaplastic ossification is a rare event in nasal polyps. The authors describe a rare case of bone formation in nasal polyp of a 28 -year-old man with chronic right-sided nasal obstruction without history of trauma or allergy symptoms. To our knowledge, this finding has been reported in a few cases in the English medical literature.[GMJ. 2013;2(2):80-82]
\end{abstract}

Keywords: Ossification; Nasal polyp; Heterotopic; Metaplasia

\section{Introduction}

$\mathrm{M}$ etaplasia is defined by the transformation of one adult tissue or cell type to another tissue or cell type. Osseous Metaplasia $(\mathrm{OM})$ is the replacement of heterotopic normal bone tissue in soft tissue [1]. Nasal polyp is a common disease that usually present in $4 \%$ of the population, followed by chronic sinonasal infection and inflammatory condition [2]. OM is an unusual event that may occur anywhere but its presence in the nasal polyps is very rare, and has been reported in only eight cases in the English language literature $[1,3]$. In this report we present a rare case of OM in nasal polyp. Informed consent was taken prior to publication from the patient.

\section{Case Presentation}

A 28-year-old man was referred to our clinic

\section{GMJ}

2013 Galen Medical Journal

Fax: +98 7312227091

PO Box 7461686688

Email:info@gmj.ir with the chief complaints of right-sided nasal obstruction, nasal discharge, and snoring during sleep for almost a year. There were no histories of trauma, prior surgery, or allergy symptoms. On anterior rhinoscopy, no abnormality was noted. In nasal endoscopy a Polyplike mass was observed in the posterior part of the right nasal cavity. The mass was attached to the inferior turbinate and extending into the nasopharyngeal space. Computed tomography (CT) scans showed a large mass lesion within the right nasal cavity that extended into nasopharynx and oropharyngeal space, and contained central ossified structure (figure 1). The patient underwent standard endoscopic surgery [4] and the mass was completely removed. The macroscopic study showed pink, firm, polypoid mass measuring $6 \times 3 \times 2 \mathrm{~cm} 3$ in size with irregular surface (figure-2). The definitive histopathology revealed a mature trabecular bone tissue covered with

\footnotetext{
Correspondence to:

Ehsan Jangholi. Young Researchers Club, Tehran

Medical Branch, Islamic Azad University, Tehran, Iran

Telephone Number:+9821-22006660

Email Address :ehsanjangholi@yahoo.com
} 
respiratory polypoid mucosa, squamous metaplasia, infiltration of inflammatory cells, and mild proliferation of mucinous glands (figure-3). In follow-ups, nasal endoscopy and CT scan were conducted at six months after surgery. These studies revealed that there were no endonasal lesions.

\section{Discussion}

Extra-skeletal bone formation is referred to as osseous metaplasia, meteplastic ossification, or ectopic bone formation [5]. Most cases of OM were reported in benign colonic and endocervical polyps [6]. Osteolipoma is the

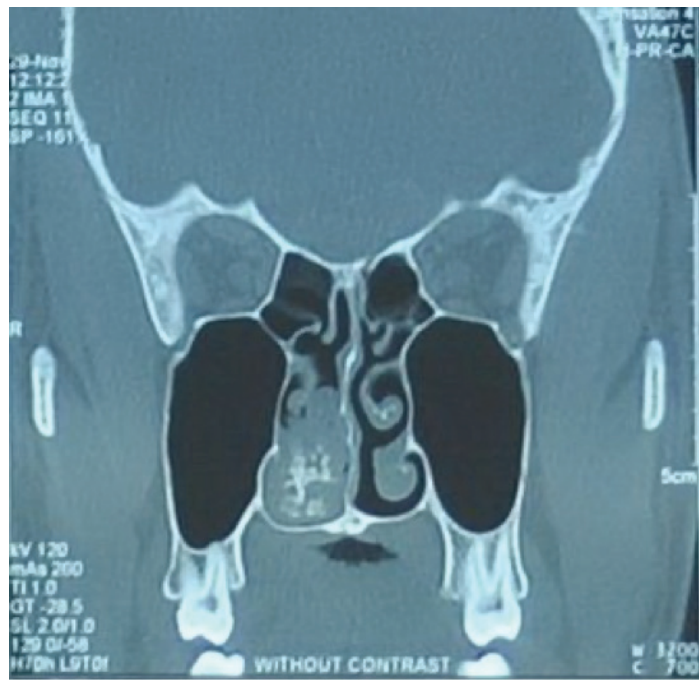

Figure-1. CT scan of Paranasal Sinuses, Coronal Slice; TumorLike Lesion in the Right Nasal Cavity with Central Ossified Structure.

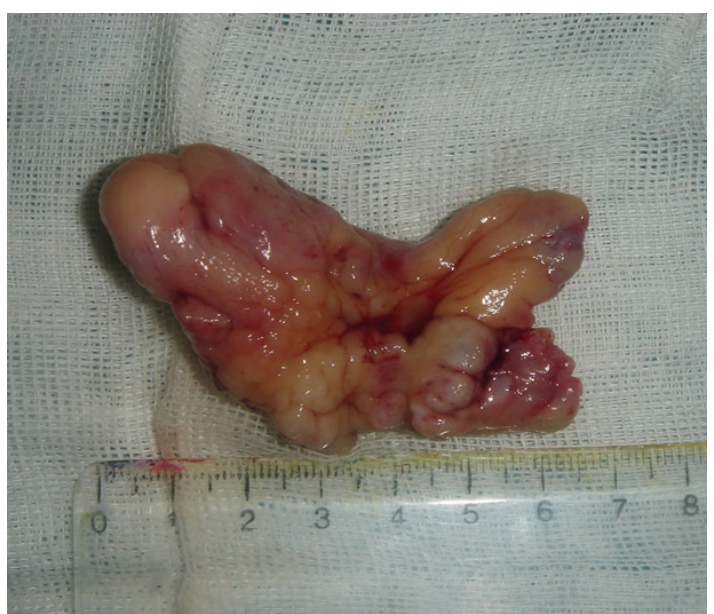

Figure-2. Polypoid Mass Measuring $6 \times 3 \times 2 \mathrm{Cm} 3$ In Size After Excision

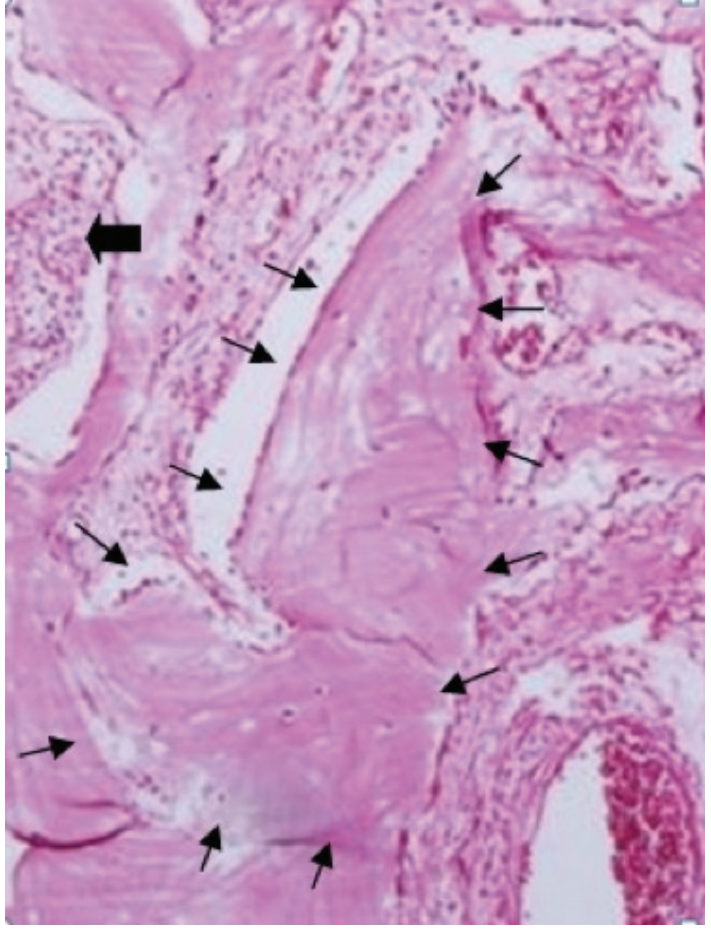

Figure-3. Histopathology (H\&E; original magnification, $\times 40$ ); Meteplastic ossification (thin arrows) in inflammatory nasal polyp (thick arrow)

most common lesion occurring with $\mathrm{OM}$ in the head and neck region [7]. Nasal polyps are common expansile lesions in the nasal cavity that form by fluid buildup in deep lamina propria of nasal mucosa and paranasal sinuses. These types of lesions usually occur following allergy, atopy, or infections. Secondary changes such as infarction, superficial ulceration, stromal cell atypia, and metaplasia of surface epithelium may also be seen in nasal polyps [8]. Although OM pathophysiology is not well known, there is a highly probable theory. According to this theory, the mesenchymatous pluripotent cells of mucosal polyp are differentiated into osteoblast progenitors under the influence of bone morphogenetic proteins (BMPs) and transforming growth factor $\beta-1$ (TGF- $\beta 1$ ); then, osteogenic signal stimulations lead to maturation of osteoblast progenitors into osteoblasts which can induce bone matrix secretion [9]. As mentioned before, the incidence of nasal polyps with OM is very low. It might be due to a low rate of diagnosis as in most cases, the polyps may be fragmented during surgery, or may not be sent for histopathological examinations. On CT, nasal 
polyps are usually seen as homogeneous soft tissue masses with smooth convex margins. But OM appears on CT scans most commonly as multiple clustered densities seen in the center of polyp [9]. Many conditions such as rhinolith (sinolith), mycetoma, inverted papilloma, chondrosarcoma, osteosarcoma, and fibrosis lesions, can mimic nasalpolyp with $\mathrm{OM}$ on $\mathrm{CT}$ and magnetic resonance (MR) images $[2,10]$, therefore pathological studies must be done to confirm the diagnosis. Hence, physicians should be aware at the time of treating nasal polyps and include osteoma and $\mathrm{OM}$ in their differential diagnoses.

\section{References}

1. Yilmaz M, Ibrahimov M, Kilic E, Ozturk O. Heterotopic bone formation (Osseous Metaplasia) in Nasal Polyps. Journal of Craniofacial Surgery. 2012;23(2):620.

2. Kim YK, Kim HJ, Kim J, Chung SK, Kim E, Ko YH, et al. Nasal polyps with metaplastic ossification: CT and MR imaging findings. Neuroradiology. 2010;52(12):1179-84.

3. MárquezMoyano J A, Cantero AN, GarridoIniesta FJ, Zamorano CP, Asin JM. Metaplastic ossification in nasal polyp. Acta Otorrinolaringol Esp. 2007; 58(6):276-7.

4. Wigand ME. Endoscopic surgery of the paranasal sinuses and anterior skull base. 2thed. New York:Thieme;2008.

5. Mercan H, Edizer DT, Kilic E, Esen T, Ramazanoglu R, Cansiz H. Osseous metaplasia in a nasal polyp: report of a rare case and review of the literature. Ear Nose Throat J. 2012;91(9):4-6.

6. Ninomiya J, Oyama T, Horiguchi J, Koibuchi Y, Yoshida T, Iijima K, et al. Two cases of breast cancer with cartilaginous and osseous metaplasia. Breast Cancer.
2005;12(1):52-6.

7. Castilho RM, Squarize CH, Nunes FD, Pinto JrDS. Osteolipoma: A rare lesion in the oral cavity. Br J Oral Maxillofac Surg. 2004;42(4):363-4.

8. De Vries N. New bone formation in nasal polyps. Rhinology. 1988;26(3):217-9.

9. Jacono AA, Sclafani AP, van de Water T, Mccormick S, Frenz D. Metaplastic bone formation in nasal polyps with histologic presence of transforming growth factor B1 (TGFB-1) and bone morphogenetic proteins(BMPs). Otolaryngol Head Neck Surg. 2001;279(3):96-7.

10. Som PM, LidovM . The significance of sinonasalradiodensities: ossification, calcification, or residual bone? AJNR Am J. Neuroradiol. 1994;15(5):917-22. 